\title{
Wind turbine doubly-fed induction generator defects diagnosis using rotor currents lissajous curves
}

\author{
Sara Kharoubi, Lamiaa El Menzhi \\ National School of Applied Sciences, Abdelmalek Essaadi University, Tangier 9000, Morocco
}

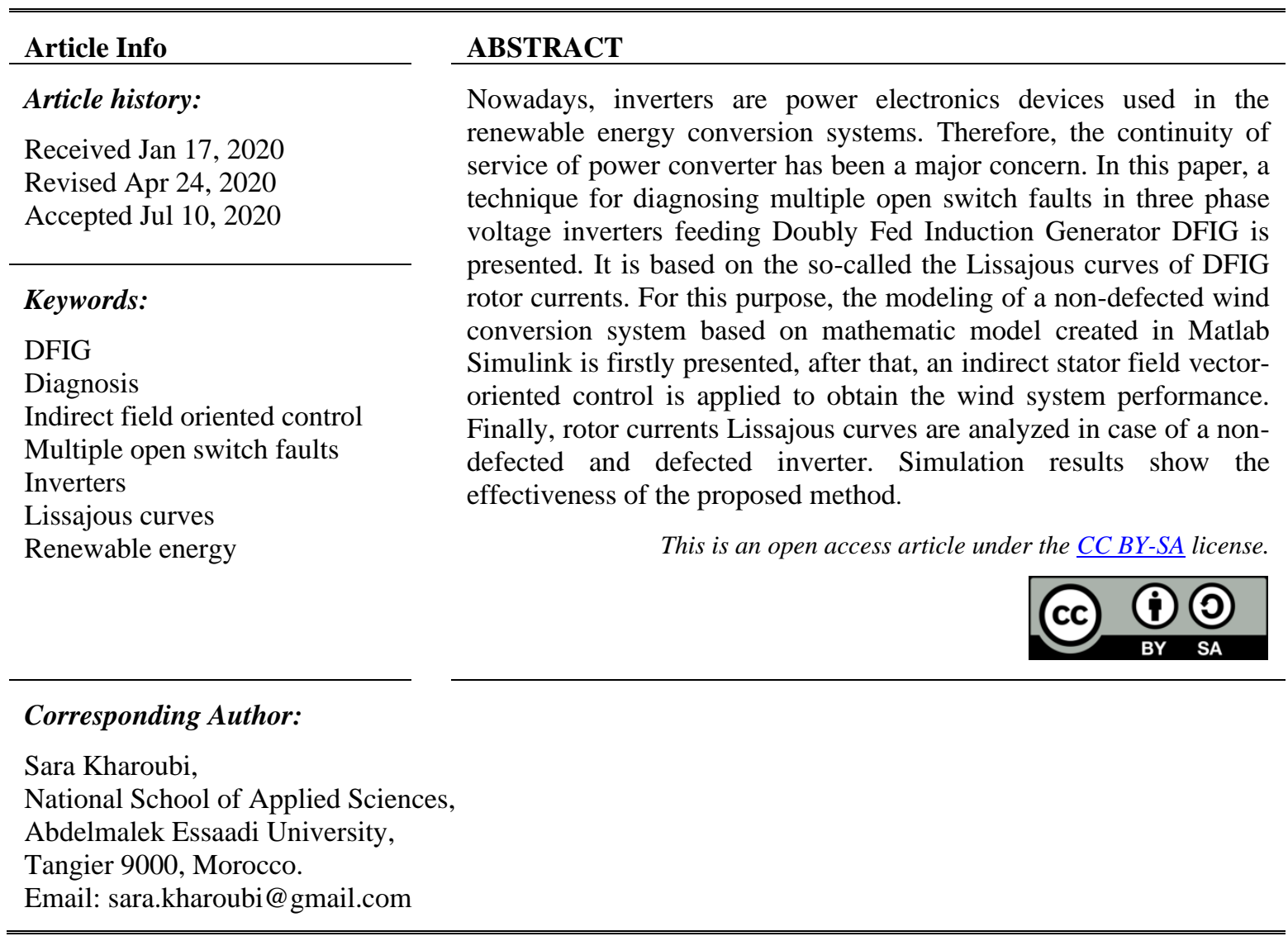

\section{INTRODUCTION}

Faced with a growing demand for energy, the industrial world is moving more and more towards renewable energies and particularly wind turbines to produce electricity. Currently, wind turbines based on the Doubly Fed Induction Generator (DFIG) are the most widely used in terrestrial wind farms. The wind energy conversion chain is a device that transforms part of the wind kinetic energy into mechanical energy available on a transmission shaft and then into electrical energy via a generator [1]. These installations are nowadays in full expansion and are of very considerable importance, whether from the point of view of electrical or economical energy requirements. However, these wind turbines may be subject to partial or total damage, an untimely shutdown of a wind chain inevitably causes inestimable losses. So, to prevent such a shutdown from being caused by electrical or mechanical failures, it is important to detect these defects early.

There have been many studies on wind energy conversion system. Whether at the level of regulation [2], of automatic generation control [3] or of faults detection [4]. Our work is part of a project that consists in modeling and simulation of the variable speed wind energy conversion chain based on the DFIG in case of a non-defected and defected converter. A lot of works has been done to detect static converters faults where many methods were used, of which we can specify: the Neural Network Approach [5], the Fuzzy Logic Approach [6] and Multidimensional Data Analysis [7]. In general, those methods are based on the trajectory of the current vector (instantaneous or average) using analytical models or pattern recognition methods to detect faults in the control circuits or power semiconductor faults (Open/ Short circuit faults 
affecting the IGBT switches) [7]. The Lissajous curves of rotor currents can also detect various inverter faults and this without disturbing the generator operation. These curves were presented in different studies such as the rotating machinery field [8], and faults diagnosis [9-10], it was also studied in [11] to detect wind turbine doubly fed induction machine under grid defects. The aim of this paper is to present Lissajous curves as a diagnosis method for detecting three phase voltage inverters feeding DFIG in the case of multiple open switches faults.

\section{CONCEPT OF WIND CONVERSION SYSTEM}

A wind system based on a DFIG is generally given under the topology illustrated by the Figure 1 . The wind turbine drives the DFIG via a gearbox, where it is connected directly to the grid by the stator and by the rotor through two three-phase statics converters controlled by pulse width modulation (PWM). One in the DFIG rotor side called Rotor Side Converter (RSC) and the other in the grid side called Grid Side Converter (GSC). Thanks to the bidirectionality of these two converters, the DFIG can operate in sub synchronous and super synchronous mode. PI type power regulators are used. They allow reaching at the same time a good dynamic and a good robustness. Rotor side converter acts as a PWM rectifier during the machine working in super synchronous mode and as an inverter during sub synchronous mode [13]. The purpose of the RSC is providing decoupled active and reactive stator power regulation Ps and Qs depending on the reference torque delivered by the PI controllers. Grid side converter acts as a PWM inverter during the machine working in super synchronous mode and as a rectifier during sub synchronous mode [13]. The purpose of the GSC is controlling the exchange of power flows with the grid via the rotor, maintaining the DC bus at a constant voltage level and imposing the reactive power Qs at 0 .

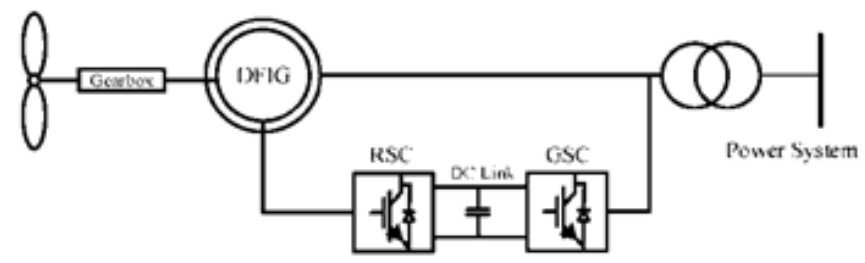

Figure 1. Wind energy conversion system using a doubly fed induction generator [12]

\section{WIND CONVERSION SYSTEM MODELING}

\subsection{Wind turbine modeling}

Our model is based on the steady state power characteristics of the turbine. The rigidity of the drive shaft is assumed infinite, the friction coefficient and the inertia of the turbine must be combined with those of the generator coupled to the turbine [14].

- The Mechanical power recovered by the turbine

$$
\begin{aligned}
& \mathrm{P}_{\text {turbine }}=\frac{1}{2} * C_{\mathrm{p}}(\lambda) * \rho * \pi * R^{2} * v^{3} \\
& \text { and } \lambda=\frac{\mathrm{R} * \Omega_{1}}{\mathrm{v}}
\end{aligned}
$$

where

$\Omega_{1}$ Speed of rotation before multiplier

$R:$ Radius of the aerogenerator

$\rho$ : Density of air, $1.225 \mathrm{~kg} / \mathrm{m}^{3}$

The coefficient of power $\mathrm{Cp}$ represents the wind turbine aerodynamic efficiency and depends on the turbine characteristic. Figure 2 represents the variation of this coefficient as a function of the speed ratio and the angle of the orientation of the blade $\beta$.

- The aerodynamic torque is:

$$
C_{\text {aero }}=\frac{P_{\text {turbine }}}{\Omega}
$$




$$
=\frac{1}{2} \frac{C_{p} * \rho * \pi * R^{2} * V^{3}}{\Omega}
$$

- The fundamental equation of dynamics

$$
\begin{aligned}
& J \frac{d \Omega_{2}}{d t}=\frac{J}{\mathrm{p}} \frac{d w_{r}}{d t}=C_{r}-C_{e m}-C_{v i s} \\
& =C_{r}-C_{e m}-f * \Omega_{2}
\end{aligned}
$$

Where

$$
\begin{array}{ll}
J & : \text { Total inertia } \\
\Omega_{2} & : \text { Speed of rotation after multiplier } \\
C_{e m} & : \text { Electromagnetic torque } \\
C_{v i s} & : \text { Viscous friction torque } \\
f & : \text { Coefficient of viscous friction* }
\end{array}
$$

*The resistant torque due to friction is modeled by a coefficient of viscous friction $\mathrm{f}$ [16].

The fundamental equation of dynamics allows determining the evolution of the mechanical speed from the total mechanical torque applied to the rotor.

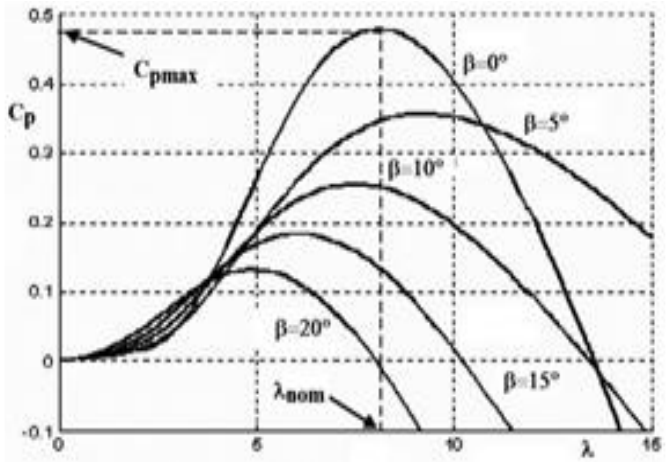

Figure 2. Characteristic of the power coefficient based on lambda variation [15]

\subsection{Modeling of doubly-fed induction machine}

Model of the asynchronous machine in Park reference frame (d, q) are [17]:

$$
\begin{aligned}
& \left\{\begin{array}{l}
V_{s d}=R_{s} * I_{s d}+\frac{d}{d t}\left(\varphi_{s d}\right)-\omega_{s} * \varphi_{s q} \\
V_{s q}=R_{s} * I_{s q}+\frac{d}{d t}\left(\varphi_{s q}\right)-\omega_{s} * \varphi_{s d}
\end{array}\right. \\
& \left\{\begin{array}{l}
V_{r d}=R_{r} * I_{r d}+\frac{d}{d t}\left(\varphi_{r d}\right)-\left(\omega_{s-} \omega_{r}\right) * \varphi_{r q} \\
V_{r q}=R_{r} * I_{r q}+\frac{d}{d t}\left(\varphi_{r q}\right)-\left(\omega_{s-} \omega_{r}\right) * \varphi_{r d}
\end{array}\right.
\end{aligned}
$$

- The electromagnetic torque equation is given by:

$$
C_{e m}=-\frac{3}{2} p * \frac{L_{m}}{L_{s}}\left(\varphi_{r d} * I_{r q}-\varphi_{r q} * I_{s d}\right)
$$

\subsection{Field oriented control}

We choose a two-phase reference frame $(\mathrm{d}, \mathrm{q})$ linked to the rotating field. The stator flux is oriented along the direct axis. So we can write:

$$
\begin{aligned}
& \left\{\begin{array}{l}
\varphi_{d s}=\varphi_{s} \\
\varphi_{q s}=0
\end{array}\right. \\
& C_{e m}=-P \cdot \frac{M}{L_{s}} \varphi_{d s} \cdot i_{q r}
\end{aligned}
$$


Active and reactive powers can be written as follows:

$$
\left\{\begin{array}{l}
P_{r}=g \frac{V_{s} * M}{L_{s}} * i_{q r} \\
Q_{r}=g \frac{V_{s} * M}{L_{s}} * i_{d r}
\end{array}\right.
$$

\section{LISSAJOUS CURVES FOR DFIG DEFECTS DIAGNOSIS}

Lissajous curves or figures, also called Bowdith curves, are the trajectories of a point on the plane whose coordinates each have a sinusoidal movement of period, amplitude and phase which may be different [18]. So by expressing a sine wave as a function of another sine wave, interesting patterns emerge. This family of curves was studied first by the American mathematician Nathaniel Bowdith in 1815, then in more detail by the French mathematician Jules-Antoine Lissajous in 1857-1858. Lissajous used a narrow stream of sand pouring from the base of a compound pendulum to produce the curves [19-20].

Lissajous curves are described by the parametric equations below [21]:

$$
x=\mathrm{A} \sin (a t+\alpha) y=\mathrm{B} \sin (b t)
$$

If the two waves are exactly the same frequency $(a=b)$, have the same amplitude $(A=B)$, but out of synch by $\pi / 2$, then one of the waves will be like a cosine, and the resultant output will be a circle:

$$
\begin{aligned}
& x=\mathrm{A} \cos (a t) y=\mathrm{A} \sin (a t) \\
& x^{2}+y^{2}=A^{2}
\end{aligned}
$$

These curves are applied in this paper to the DFIG rotor three-phase currents. For this purpose, it is necessary to apply the Concordia transformation [22] to the rotor basic currents $I_{r a b c}$, in order to obtain the rotor currents Concordia components $\left(I_{r \alpha}, I_{r \beta}\right)$ such as:

$$
\left[\begin{array}{l}
I_{r \alpha} \\
I_{r \beta}
\end{array}\right]=\frac{\sqrt{2}}{3}\left[\begin{array}{ccc}
1 & -1 / 2 & -1 / 2 \\
0 & \frac{\sqrt{3}}{2} & -\frac{\sqrt{3}}{2}
\end{array}\right] *\left[\begin{array}{c}
I_{r a} \\
I_{r b} \\
I_{r c}
\end{array}\right]
$$

\section{SIMULATION RESULTS}

In order to show the effectiveness of the proposed method, simulations of the wind energy conversion chain were carried out on Matlab/Simulink.

\subsection{Free-deffects operation}

This case is a reference to which the defected inverter feeding the DFIG cases are compared. Figure 3 represent respectively the system characteristics and rotor currents Lisssajous curve during free-defects operation.

\subsection{Discussion}

During the transient regime, the rotor speed is slightly pulsating, presenting beats at the first moment of starting, after that the speed reaches the steady state by stabilizing at the nominal value. The curve of the electromechanical torque presents at startup large beats in a short time interval then stabilizes at a negative value which reflects the generator mode. At startup, the bus voltage increases exponentially for a few seconds and then returns to a fixed reference value. The reactive power set point will be maintained at zero to ensure a unit power factor on the stator side so as to optimize the quality of the energy returned on the grid [23]. The active power set point must keep the power factor of the wind turbine optimal. The Lissajous curve of Doubly Fed Induction Generator rotor currents Concordia components, as shown in Figure 3 (b), has a shape of two circles of which the one inside has six knots: the number of the inverter switches. 

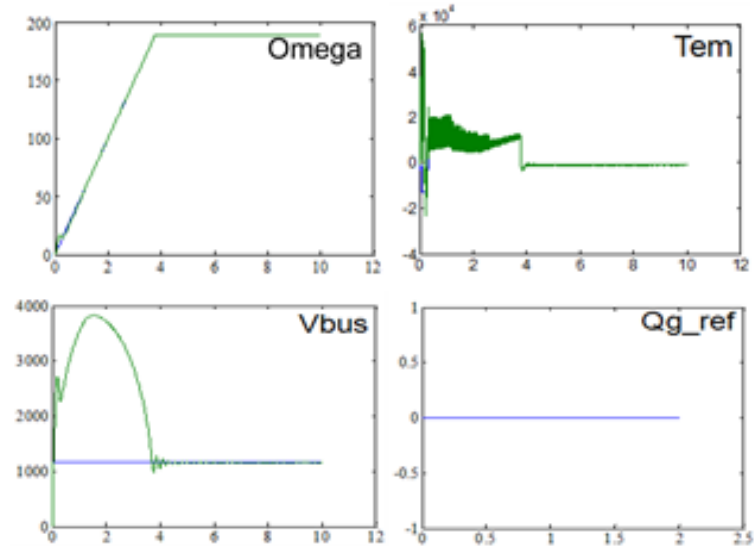

(a)

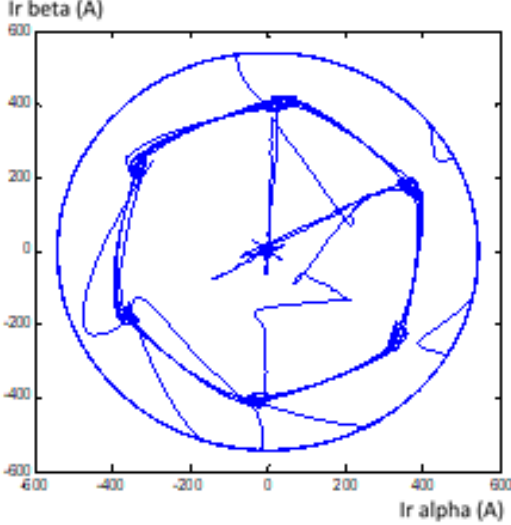

(b)

Figure 3. Free-defects operation, (a) The dynamic behavior of the DFIG, (b) Lissajous curve of DFIG rotor currents

\subsection{Faulty operation}

In this application, we are interested in the hypo-synchronous generator operation, so as to treat only the transfer of rotor power in a single direction (Grid to Rotor). The grid side converter will therefore be a simple unidirectional rectifier. The DC bus voltage is therefore kept fixed and we are interested only in the control of the rotor side converter. A converter such as the PWM inverter is likely to have structural defects such as power semiconductor faults (switches) short circuit and/or open circuit [24], and therefore this type of malfunction may cause damage to the entire production system if the personnel is not notified and an untimely shutdown is produced [25]. A study was devoted to the detection and diagnosis of faults in static converters in an aspect closer to the physics of the electronic power component and the module which described the mechanisms of the main failures. This study has shown that the temperature of the environment as well as temperature variations due to thermal cycles are the main causes of failures [7]. In this paper, inverter faulty operations are considered in the case of multiple open switches that occur at the same leg and at different legs.

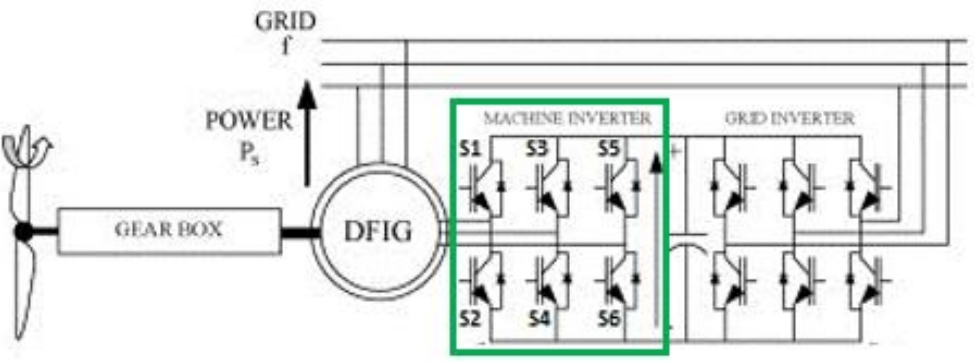

Figure 4. The six switches $\left\{S_{1}\right.$ to $\left.S_{6}\right\}$ of the rotor side converter concerned by our faulty operation study [26]

Open-circuit faults attacking the IGBT switches may occur when the IGBT is disconnected, is damaged, or had a problem in its grid control signal. This type of fault is very difficult to recognize directly because the motor can continue to run but with a degradation of its performance due to the occurrence of fluctuations in the mechanical parameters as well as a variation in the currents where the currents of the other two healthy legs take high values to maintain the average torque and the speed. In the presence of this type of fault, the starting of the motor cannot always be guaranteed, everything will depend on the value of the torque which can be close to zero for certain rotor position [27]. An IGBT open-circuit fault in a switch is introduced by removing its gate signal [28]. The rotor currents Concordia components Lissajous curves indicate the inverter faulty situation. A free-defects operation is represented by a six knots circle inside a 
perfect one. If an inverter fault takes place, there is a change in the rotor currents. Therefore, a change in the circle shape proves the presence of inverter defect.

Inverter Single Switch Fault. The figures below show the rotor currents Lissajous curve in the case of different level single switch fault. When the fault occurs, the circle with six knots becomes a circle with 5 knots Figure 4. The orientation of the circle missed knots depends on the defected switch location. In the case of one upper switch fault, the missed knot appears at the bottom (a). In the case of one lower switch fault, the missed knot appears at the top (b).

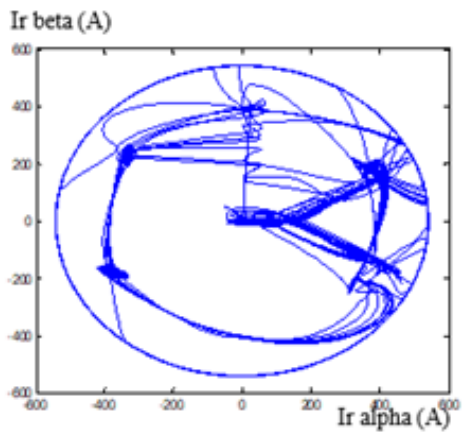

(a)

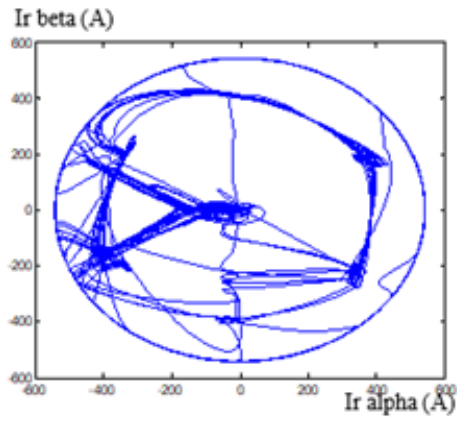

(b)

Figure 4. Lissajous curves of rotor currents Concordia Components,

(a) Case of a DFIG fed by $S_{1}$ switch defected inverter, (b) Case of a DFIG fed by $S_{2}$ switch defected inverter

Inverter Double Switches Fault in the Same Leg. The Figure 5 shows the rotor currents Lissajous curve in the case of the same leg double switches faults. When the fault occurs, the circle with six knots becomes a circle with 4 knots, it's close to a shape of butterfly with knot inside Figure 5 . The orientation of the circle depends on the defected switches location.

Inverter Double Switches Fault in different Legs. The Figure 6 shows the rotor currents Lissajous curve in the case of different leg double switches fault. When the faults occur, the circle with six knots becomes a circle with 4 knots. The orientation of the circle missed knots depends on the defected switches location. In the case of two upper switches fault, the missed knots appear at the top (a). In the case of two lower switches fault, the missed knots appear at the bottom (b). In the case of one upper switch and one lower switch faults, the obtained shape is presented in (c).

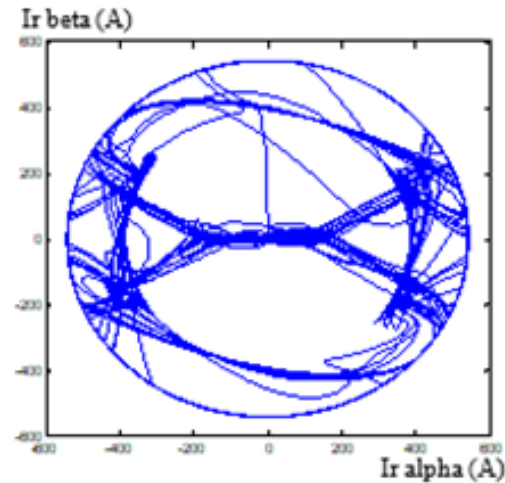

(a)

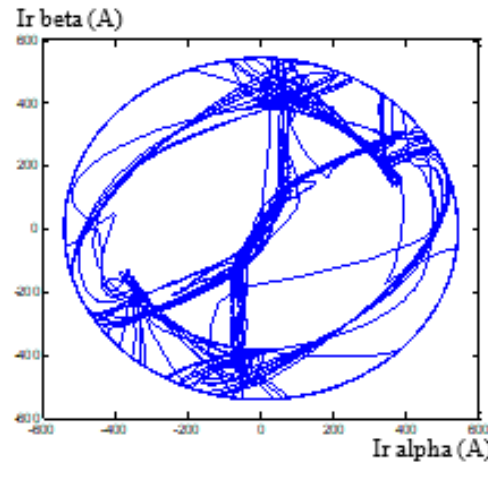

(b)

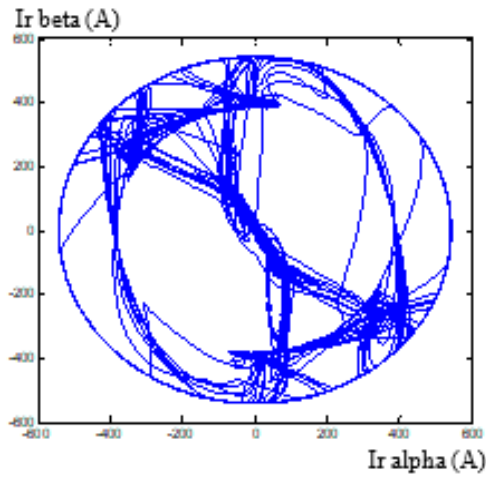

(c)

Figure 5. Lissajous curves of rotor currents,

(a) Case of a DFIG fed by $S_{1}$ and $S_{2}$ switches defected inverter, (b) Case of a DFIG fed by $S_{3}$ and $S_{4}$ switches defected inverter, (c) Case of a DFIG fed by $S_{5}$ and $S_{6}$ switches defected inverter 


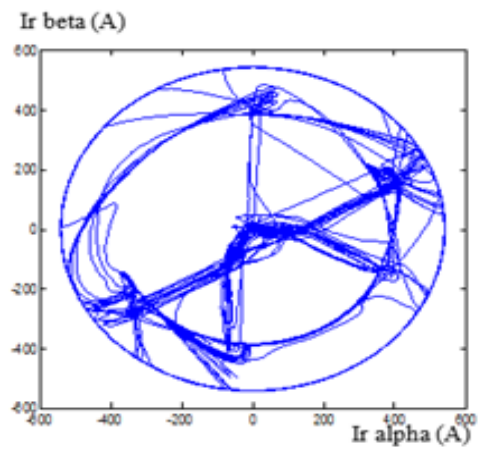

(a)

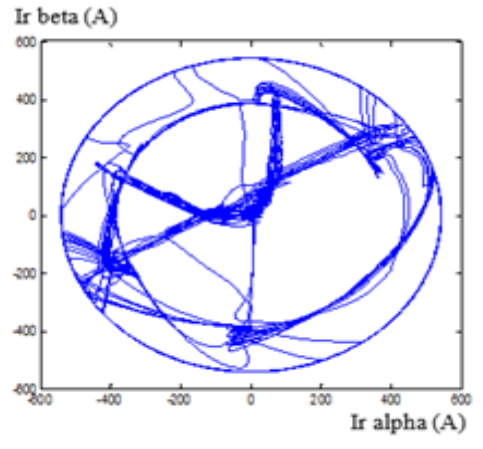

(b)

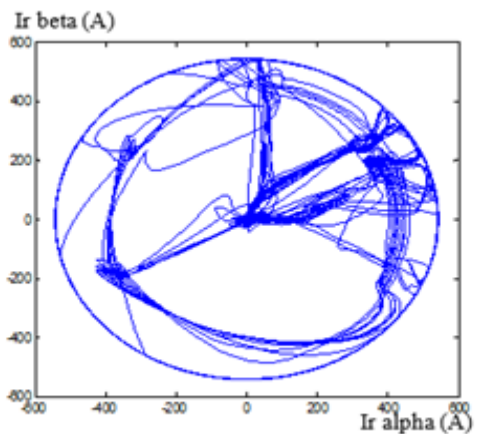

(c)

Figure 6. Lissajous curve of rotor currents, (a) Case of a DFIG fed by $S_{1}$ and $S_{3}$ switches defected inverter,

(b) Case of a DFIG fed by $S_{2}$ and $S_{4}$ switches defected inverter, (c) Case of a DFIG fed by $S_{1}$ and $S_{4}$ switches defected inverter

\section{CONCLUSION}

In the first part of this paper we studied the operating mode of the wind energy conversion system namely the model of the variable speed turbine and the model of the Doubly Fed Induction Generator. In the second part, a method was developed for detecting three phase inverter Single and Multiple Open Switches faults, based on the rotor currents Concordia components Lissajous curves. In the case of a free-defects operation, the Lissajous curve has a shape of two circles of which the one inside has six knots (exactly the number of the inverter switches). The knots number decreases and the circle orientation changes according to the number of the inverter defected switches (single or double) and their location. We are still pursuing simulations of the inverter feeding Doubly Fed Induction Generator in the case of Short Circuit Switches Fault before moving to the Grid Side Converter to do the complete inverter faulty operation study. To complete the project, a system of supervision and decision making regarding the type of defect and its location must be established.

\section{REFERENCES}

[1] Mustapha Hatti, "Smart Energy Empowerment in Smart and Resilient Cities," Springer Science and Busniss Media $L L C, 2020$

[2] S. A. Gawish, S. M. Sharaf and MS El-Harony. "Experimental Results of a Wind Energy Conversion System with STATCOM Using Fuzzy Logic Controller," Bulletin of Electrical Engineering and Informatics, Vol. 5, No. 3, pp. 271-283, 2016.

[3] S. Kail, A. Bekri and A. Hazzab. "Study of automatic generation control in two area power system with DFIGbased wind energy conversion." International Journal of Power Electronics and Drive System (IJPEDS)”, Vol. 10, No. 4, pp. 2118-2125, 2019.

[4] N. F. Fadzail, S. Mat Zali, M. A. Khairudin and N. H. Hanafi. "Stator winding fault detection of induction generator based wind turbine using ANN." Indonesian Journal of Electrical Engineering and Computer Science, Vol. 19, No. 1, pp. 126-133, , July 2020.

[5] H. K. Khleaf, A. K. Nahar and A. S. Jabbar. "Intelligent control of DC-DC converter based on PID-neural network." International Journal of Power Electronics and Drive System (IJPEDS), Vol. 10, No. 4, pp. 2254-2262 2019.

[6] O. Salama, A. Tabyaoui and M. Benchagra. "Control Methods on Three-phase Power Converters in Photovoltaic Systems." International Journal of Power Electronics and Drive System (IJPEDS), Vol. 9, No. 4, pp. 1851-1865, 2018

[7] TRIGEASSOU Jean-Claude. "Diagnostic des machine électriques.” France, Collection Lavoisier, 04-2011, 376 p.

[8] H. A. H. Al-Khazali and M. R. Askari, "Geometrical and Graphical Representations Analysis of Lissajous Figures in Rotor Dynamic System.” Journal of Engineering (IOSR), vol. 2, no. 5, pp. 971-978, 2012.

[9] L. El Menzhi and A. Saad. "Lissajous Curve of an Auxiliary Winding Voltage Park Components for Doubly-Fed Induction Machine Electrical Faults Diagnosis." The Journal of Advanced Materials Research, vol. 860-863, pp. 2223-2231, 2014.

[10] F. El Hammouchi, L. El Menzhi, A. Saad, Y. Ihedrane and B. Bossoufi. "Wind turbine doubly-fed asynchronous machine diagnosis defects using stator and rotor currents lissajous curves." International Journal of Power Electronics and Drive System (IJPEDS), Vol. 10, No. 2, pp. 961-970, June 2019.

[11] F. EL Hammouchi, L. El Menzhi and A. Saad. "Diagnosis Method for Wind Turbine Doubly Fed Induction Generator under Grid Defects.” International Journal of Information Science \& Technology-IJIST, Vol.3 No.3, 2019.

Wind turbine doubly-fed induction generator defects diagnosis using rotor currents... (Sara Kharoubi) 
[12] Qin B., Li H., Zhou X., Li J. and Liu W. "Low-Voltage Ride-Through Techniques in DFIG-Based Wind Turbines: A Review." Appl. Sci. vol. 10, p. 2154, 2020.

[13] K. Shanmukha Rao and M. vijay Kumar. "Analysis of Doubly Fed Induction Generator under Varies Fault Conditions." Journal of Engineering Research and Applications, Vol. 3, No. 6, pp. 2102-2106, Nov-Dec 2013.

[14] O. Anaya-Lara, N. Jenkins, J. Ekanayake, P. Cartwright and M. Hughes. "Wind energy generation: Modeling and control." Jhon Wiley \& Sons, Ltd, UK, 2009.

[15] M. Adjoudj, M. Abid, A. Aissaoui, Y. Ramdani and H. Bounoua. "Commande par Mode Glissant d'une Machine Asynchrone à Double Alimentation Monté dans une Eolienne.” Revue 'Nature et Technologie', №2, pp. 27 - 34, 2010.

[16] F. M. Hughes, O. Anaya-Lara, N. Jenkins and G. Strbac. "Control of DFIG-based wind feneration for power network support." IEEE Transaction on Power Electronics, vol.20, pp. 1958-1968. November 2005.

[17] H. Abu-ub, M. Malinowski and K. Al-Haddad. "Power Electronics for Renewable Energy Systems, Transpotation and Industrial Applications." IEEE, by John Wiley \& Sons, Ltd, 2014.

[18] P. B. Varvadiya, P. D. Patal and A. McEwan. "Measurement of the speed of sound in air medium using Lissajous Patterns." SSRG International Journal of Electrical and Electronics Engineering (SSRG-IJEEE), vol. 2, no. 11, Novembre 2015

[19] H. Cundy and A. Rollett. "Lissajous's Figures in Mathematical Models." 3rd ed. Stradbroke, England: Tarquin Pub. 1989.

[20] A. Gray, "Modern Differential Geometry of Curves and Surfaces with Mathematica", 2nd ed. Boca Raton, FL: CRC Press, 1997.

[21] H. G. Yiyang. "Demonstrating Lissajous Figures with Matlab and Their Applications." Journal of China Science and Technology Information, Electronic \& Industrial College, Yiyang Hunan 413054, 2, China, 2008.

[22] B. Bossoufi, M. Karim, S. Ioniłă and A. Lagrioui. "Performance Analysis of the Direct Torque Control and the Space Vector Modulation for Permanent Magnet Synchronous Motor Drive." University of Pitesti Scientific Bulletin: Electronics and Computers Science, vol.10, no. 2, pp 23-34, 2010

[23] G. Abad, J. Lopez, M. A. Rodiguez, L. Marroyo and G. Iwanski. "Doubly Fed Induction Machine Modeling And Control for Wind Enegy Generation.” New Jersey, John Wiley \& Sons, Hoboke, 2011 by the Institute of Electrical and Electronics Engineers, Inc, 2011.

[24] W. Zhang, D. Xu, P. N. Enjeti, H. Li, J. T. Hawke and H. S. Krishnamoorthy. "Survey on fault-tolerant techniques for power electronic converters." IEEE Transactions on Power Electronics, vol. 29, no. 12, pp. 6319-6331, 2014.

[25] Mr. Aouane N. and Mr. Chamkha S. "Détection, localisation et reconfiguration de défauts onduleur à deux niveaux appliqué dans la commande de la machine asynchrone à cage." Faculté des Sciences de l'Ingénieur, Université M'HAMED BOUGARA-BOUMERDES, Algérie, Juin 2017.

[26] B. D. E. Cherif and A. Bendiabdellah. "Detection of Two-Level Inverter Open-Circuit Fault Using a Combined DWT-NN Approach.” Journal of Control Science and Engineering, vol. 2018, Article ID 1976836, p. 11.2018

[27] F. Potiers, T. Bouaouiche and M. Machmoum. "Advanced control of a doubly -fed induction generator for wind energy conversion.” Electric Power Systems Research, vol. 79, no. 7, pp. 1085-1096, July 2009.

[28] L. EL Menzhi and A. Saad. "Lissajous Curve of an Auxiliary Winding Voltage Park Component for Diagnosing Multiple Open Switches Faults in Three Phase Inverter." Applied Mechanics and Materials Vol. 672-674, pp 12241233, 2014.

\section{BIOGRAPHIES OF AUTHORS}

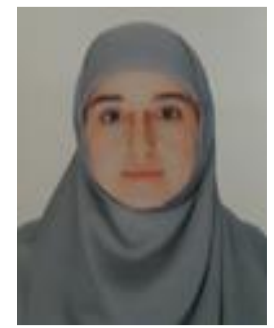

Sara Kharoubi was born in Morocco on September 9th, 1991. In 2015, She received the Engineer degree in Mechatronic Engineering from the National School of Applied Sciences (ENSA) Abdelmalek Essaadi University of Morocco in Tétouan. She is a PhD student in electrical engineering at Innovative Technologies Laboratory (LTI) of ENSA Tangier since December 2016. She is interested in electrical machines control, on line diagnosis defects in wind turbines, and their integration in grid.

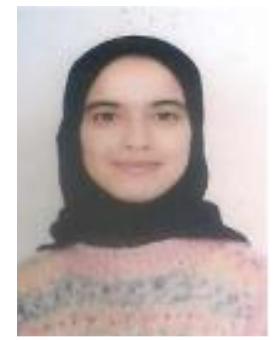

Lamiaa El Menzhi is a professor in AbdelamalekEssaadi University in Morocco since 2010. On 2002, She got her High Deepened Studies Diploma in electrical machines in electrical engineering from the High National School of Electricity and Mechanics ENSEM in Hassan 2 University in Casablanca. From 2002 until 2004, she was a research student in one of the universities in japan. On 2009, she obtained her Doctor degree, then her Habilitation as a professor researcher on 2016 from Hassan 2 University in Casablanca (ESEM). She is interested in electrical machines control and on-line diagnosis either used as a motor or a generator in wind turbines. Lamiaa El Menzhi is a member and advisor of the Moroccan Center of Polytechnical Research and Innovation since 2015. 